\title{
Modelo adaptativo de conforto para avaliação in loco de espaços urbanos abertos
}

\author{
Adaptative comfort model for on-site evaluation of urban \\ open spaces
}

\section{Leonardo Marques Monteiro Marcia Peinado Alucci}

\section{Resumo}

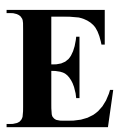

spaços urbanos abertos possibilitam menor controle das variáveis ambientais do que espaços fechados, que apresentam maior grau de confinamento. Por outro lado, as possibilidades de adaptação dos usuários nos espaços abertos acabam sendo maiores devido aos seus usos predominantes. O objetivo deste artigo é verificar possíveis meios de adaptação térmica, tais como atividades, vestimentas e aclimatação, para a proposição de ajustes na Temperatura Equivalente de Globo, que é utilizada para avaliação in loco de espaços urbanos abertos. Foram realizados levantamentos de campo com quantificação de variáveis ambientais e aplicação de questionários, e comparação dos resultados de modelos preditivos e diferentes bases empíricas. $\mathrm{O}$ estudo considerou diferentes atividades físicas, diferentes conjuntos de vestimenta e diferentes condições de aclimatação. Os resultados indicaram a necessidade de ampliações na base empírica para os dados relativos às atividades e vestimentas. Com relação à aclimatação, considerando a temperatura do ar média horária dos trinta dias anteriores a que estavam expostos os entrevistados, sua verificação demonstrou que, dentro dos limites do estudo, a abordagem adotada de propor ajustes na Temperatura Equivalente de Globo, é adequada,. Os resultados do modelo ajustado com base nos resultados de aclimatação dos entrevistados apresentaram correlação mais alta com as bases empíricas do que os resultados do modelo originalmente proposto.

Palavras-chave: Conforto térmico. Espaços abertos. Modelos preditivos. Temperatura equivalente.

Leonardo Marques Monteiro Faculdade de Arquitetura e Universidade de São Paulo Cidade Universitária, Rua do Lago,

São Paulo - SP - Brasil CEP 05508.080

Tel : (11) 3091-4538

E-mail: leo4mm@gmail.com

Marcia Peinado Alucci Faculdade de Arquitetura e
Urbanismo

Universidade de São Paulo Tel.: (11) 3091-4538 E-mail: marciaalu@gmail.com

Recebido em 10/10/11

Aceito em 03/02/12

\section{Abstract}

Open urban spaces allow less control of environmental variables than enclosed spaces, which present a higher degree of confinement. By contrast, the possibility of users' adaptation in open spaces is higher due to their predominant uses. The aim of this paper is to investigate possible means of thermal adaptation, such as activities, clothing, and acclimation, in order to propose adjustments in the Equivalent Globe Temperature, which is used in the assessment of outdoor urban spaces. Data collection involved the quantification of environmental variables and questionnaires, and a comparison of the results of predictive models and different empirical basis. The study considered different physical activities, different sets of clothing, and various conditions of acclimation. The results indicated the need to expand the empirical basis for the data on activities and clothing. With regards to acclimation, considering the average hourly temperature to which the interviewees were exposed in the 30 previous days, it was observed that within the limits of this investigation, the approach of proposing an adjustment to the equivalent globe temperature is appropriate. The results of the adjusted model considering acclimatization showed higher correlation with empirical data than those in the original proposed model.

Keywords: Thermal comfort. Outdoors. Predictive models. Equivalent temperature. 


\section{Introdução}

Os estudos de conforto térmico em espaços urbanos abertos, sobretudo aqueles relacionados ao microclima e à sensação térmica dos usuários, desenvolveram-se sobremaneira em nosso país nos últimos anos. Prata-Shimomura, Monteiro e Frota (2009) consideram variações em situações microclimáticas urbanas reais, comparando-as com situações simuladas em túnel de vento, e utilizam o índice de temperatura equivalente fisiológica para testar a variação da velocidade do ar na sensação térmica do pedestre. Monteiro e Alucci (2009a) apresentam a consideração de variáveis ambientais em espaços abertos para a proposição e verificação de modelo preditivo de sensação térmica. Os mesmos autores (MONTEIRO; ALUCCI, 2009b) consideram a taxa metabólica e o isolamento térmico da roupa em situações urbanas. Brusanti e Fontes (2009) exploram a questão do conforto térmico em espaços públicos de permanência na cidade de Bauru, SP, destacando-se aqui as diferenças que foram encontradas pelas autoras entre a sensação e a satisfação térmica. Shimakawa e Bueno-Bartholomei (2009) aplicam modelos preditivos (PET e PMV) para estudo de caso em Presidente Prudente, SP, considerando em seus questionários aspectos sociais e questões relacionadas à preferência térmica e de conforto. Dacanal et al. (2009) discutem um estudo de caso de conforto térmico em espaços livres públicos em Campinas, SP, concluindo "que o prazer de estar em um espaço livre público, associado ao tempo livre, decorre de uma somatória de fatores, dentre os quais o microclima faz parte, mas não é decisivo para a percepção do conforto".

Barbosa, Amo e Labaki (2010) avaliam o nível do conforto dos usuários em seis pontos distintos de praça em Campinas, utilizando o voto médio estimado. Verificam a influência da vegetação e as limitações do índice utilizado. Rossi (2010) realiza extensa série de levantamentos empíricos em espaços abertos na cidade de Curitiba e propõe, no desenvolvimento futuro dos trabalhos de pesquisa, chegar a calibrações para os índices SET*, PMV e PET, e, ainda, modelagem própria baseada em regressão estatística dos dados coletados e dos questionários aplicados. Hirashima (2010) propõe calibração do índice de conforto térmico PET para os espaços abertos de Belo Horizonte, MG, por meio de medições em campo e aplicação simultânea de questionários, em dias representativos de cada uma das quatro estações, durante 2009 e 2010, e em duas áreas contrastantes com relação a características morfológicas. Conclui definindo o limite superior do intervalo confortável, segundo a autora, com o valor de 30,5 ${ }^{\circ} \mathrm{C}$; o intervalo referente a calor foi delimitado pelos valores de $30,5{ }^{\circ} \mathrm{C}$ a $35^{\circ} \mathrm{C}$, sendo $35^{\circ} \mathrm{C}$ o limite inferior do intervalo referente a muito calor. Os intervalos referentes às situações climáticas de baixas temperaturas, assim como o limite inferior do intervalo de conforto não foram definidos. Monteiro e Alucci (2010) verificam comparativamente os resultados de bases empíricas laboratoriais e de campo, estabelecidas na cidade de São Paulo. Para tanto, consideram-se modelos preditivos desenvolvidos, adaptados ou utilizados em pesquisas de conforto térmico em espaços abertos. Ao mesmo tempo, verificam-se comparativamente os referidos modelos, com indicação de uso daqueles que apresentaram resultados mais significativos para diferentes aplicações.

Rossi, Krüger e Nikolopoulou (2011a) realizaram pesquisa para analisar o conforto térmico de transeuntes em ruas de pedestres em Curitiba, PR. O objetivo é definir faixas de estresse térmico para a cidade de Curitiba, propondo a calibração das faixas do índice UTCI (Universal Thermal Climate Index) para as condições térmicas da cidade e verificando a porcentagem aceitável de pessoas insatisfeitas com o ambiente térmico de espaços abertos. Os resultados mostram que é possível definir as faixas de estresse térmico a partir das respostas reais de sensação térmica. Também indicam a necessidade de calibração do índice UTCI e que $20 \%$ de pessoas insatisfeitas com o ambiente térmico seria um possível limiar para PPD em espaços abertos. Rossi, Krüger e Bröde (2011b) apresentam resultados obtidos por meio de coleta de campo em diferentes pontos de ruas de pedestres da cidade de Curitiba com o objetivo de verificar a existência de diferenças climáticas nos locais monitorados e sua relação com as características urbanas, além de sugerir ações que melhorem o conforto térmico local. As análises entre dois pontos monitorados no mesmo dia ajudam a entender as diferenças significativas observadas entre as variáveis climáticas monitoradas. Hirashima, Assis e Ferreira (2011) apresenta trabalha cujo objetivo foi a proposição de procedimentos para medição de variáveis microclimáticas urbanas, coleta de variáveis individuais e subjetivas, e tratamento dos dados obtidos, com vistas à calibração do índice temperatura equivalente fisiológica (PET), para espaços abertos do município de Belo Horizonte. $\mathrm{O}$ método geral utilizado para o desenvolvimento desse estudo foi o método indutivo experimental. Como resultados, foram delimitados intervalos do índice térmico PET para diferentes graus de percepção térmica para Belo Horizonte. Rancura e Labaki (2011) tiveram por objetivo analisar as 
condições de conforto térmico e sua diferente percepção entre trabalhadores e usuários nas feiras livres que acontecem na cidade de Indaiatuba, SP, nos fins de semana. A metodologia constou da medição de parâmetros ambientais e aplicação de questionários junto aos trabalhadores e usuários para identificar a atividade desenvolvida, a vestimenta, a sensação e a satisfação térmica. Os resultados permitiram correlacionar a sensação térmica real (ASV - actual sensation vote) ao índice PET (physiological equivalent temperature), e também demonstrou a diferença entre a sensação térmica real entre trabalhadores e usuários.

Fontes e Brussantin (2011) apresentam um estudo de caso em um espaço público arborizado, na cidade de Bauru, SP, que analisa os limites do conforto térmico real, através de questionários, calculado utilizando-se o índice preditivo PET (temperatura fisiológica equivalente), através do software RayMan 1.2. Os resultados evidenciam diferenças significativas entre o conforto real e o calculado, e limites amplos para a neutralidade térmica. A pesquisa revela, ainda, a importância da ampliação da escala de valores para a definição da sensação térmica real (ASV), em futuros estudos, objetivando melhor ajuste nos limites de conforto/desconforto e calibração do índice PET. Shinyashiki e Bueno-Bartholomei (2011) apresentam dados obtidos no inverno de 2009, na Praça Nove de Julho, um local arborizado e muito movimentado no centro da cidade de Presidente Prudente, SP. A partir do monitoramento das condições microclimáticas (temperatura do ar, temperatura de globo, umidade relativa do ar, velocidade do ar, radiação global) e da aplicação de questionários sobre a sensação, a percepção e a preferência térmica, junto aos usuários, os limites de conforto térmico real foram avaliados e correlacionados com o conforto térmico calculado, no sentido de identificar diferenças entre as condições de conforto objetiva e subjetiva, chegando-se à conclusão de que o modelo preditivo que mais se aproximou do conforto declarado pelos entrevistados, nesse trabalho, foi o PMV (voto médio estimado). Wolfram e Monteiro (2011) focam no uso da vegetação como elemento de adequação térmica de espaços abertos. O objetivo do trabalho foi verificar a influência da arborização para o conforto do pedestre no meio urbano. $\mathrm{O}$ método utilizado é indutivo, por meio de levantamentos de campo de variáveis microclimáticas ambientais, apoiado por método dedutivo, por meio de comparações entre os resultados levantados nos diferentes ambientes, considerando o modelo preditivo de sensação térmica TEP e a representatividade dos dados em função das condições climáticas anuais típicas da cidade de São Paulo.

Este artigo, considerando diferentes condições ambientais urbanas de espaços abertos no Bairro da Luz, em São Paulo, SP, verifica a possibilidade de diferentes meios de adaptação térmica. Dessa forma, considera diferentes atividades físicas, que implicam diferentes taxas metabólicas (ISO 8996 (INTERNATIONAL..., 1990)), diferentes conjuntos de vestimenta, que caracterizam diferentes valores de isolamento térmico (ISO 9920 (INTERNATIONAL..., 1995)), e diferentes condições de aclimatação, caracterizados por meio da temperatura do ar média dos 30 dias anteriores aos levantamentos (MONTEIRO, 2008). Ressaltase que em espaços urbanos abertos, ainda que o controle das variáveis ambientais seja menor do que em espaços fechados, que apresentam maior grau de confinamento, as possibilidades de adaptação dos usuários acabam sendo maiores devido aos usos desses espaços.

O objetivo deste artigo é verificar possíveis meios de adaptação térmica (atividades, vestimentas, aclimatação) para a proposição de ajustes na temperatura equivalente de globo. Esse modelo preditivo de sensação térmica baseado na regressão estatística de dados empíricos para aplicação em levantamentos in loco em espaços urbanos abertos na cidade de São de Paulo foi proposto por Monteiro (2011). A contribuição deste trabalho, dentro do panorama histórico e estado da arte, é, por basear-se apenas na temperatura de globo, requerer a utilização de apenas um instrumento quando o objetivo dos levantamentos empíricos for estabelecer correlações com sensações térmicas, facilitando, assim, a execução dos levantamentos.

\section{Método}

Foram realizados levantamentos de campo em espaços abertos urbanos no Bairro da Luz, em São Paulo, SP. A base empírica estabelecida abrange conjunto de dados de levantamentos realizados em dias de verão e de inverno, considerando-se variáveis ambientais e aplicação de questionários.

\section{Levantamentos de campo}

Nesta pesquisa, realizaram-se levantamentos de campo em situações urbanas, aplicando-se questionários a usuários dos espaços em questão. A base empírica estabelecida abrange um conjunto de dados de levantamentos realizados em dias de verão e de inverno no Bairro da Luz, em São Paulo. Esses levantamentos são considerados em detalhes por Monteiro e Alucci (2010) e aqui 
apresentados sucintamente para compreensão dos desenvolvimentos realizados.

Considerando o bairro em questão, e devido à quantidade de equipamentos disponíveis, foram estabelecidas três bases para levantamentos simultâneos, sendo ao todo abarcados cinco locais distintos, selecionados com base na diversidade de configurações tipológicas e que se configuravam como de passagem e/ou de permanência. Dessa forma, os levantamentos de verão foram realizados em uma rua (Rua dos Andradas), em uma praça (Praça Sala São Paulo) e em um parque (Parque da Luz). Ressalta-se que o primeiro local é predominantemente de passagem, o terceiro é predominantemente de permanência, e o segundo apresenta as duas situações. Nos levantamentos de inverno, devido à menor quantidade de pessoas disponíveis para sua realização, somada às dificuldades encontradas para o gerenciamento simultâneo dos levantamentos nos diferentes locais, optou-se pela seleção de locais mais próximos entre si, mas que mantivessem as características inicialmente estabelecidas. Dessa forma, buscaram-se a diversidade tipológica e a heterogeneidade de usos. Ao mesmo tempo, optouse por manter-se um mesmo ponto levantado no período de verão, para que comparações diretas pudessem ser realizadas. Assim, manteve-se o ponto do parque (Parque da Luz), com uso predominante de permanência. Os demais pontos para realização dos levantamentos foram estabelecidos considerando-se uma rua e uma praça, apresentando, assim, características tipológicas e de uso distintas, sendo um local de passagem e de permanência (Praça da Luz, na entrada do Parque da Luz) e um local de passagem (na entrada da Estação da Luz). A Figura 1 apresenta os locais levantados empiricamente no Bairro da Luz.

As Figuras 2 a 5 indicam os ambientes físicos e as condições de exposição ao céu de cada uma das bases levantadas no verão e no inverno.

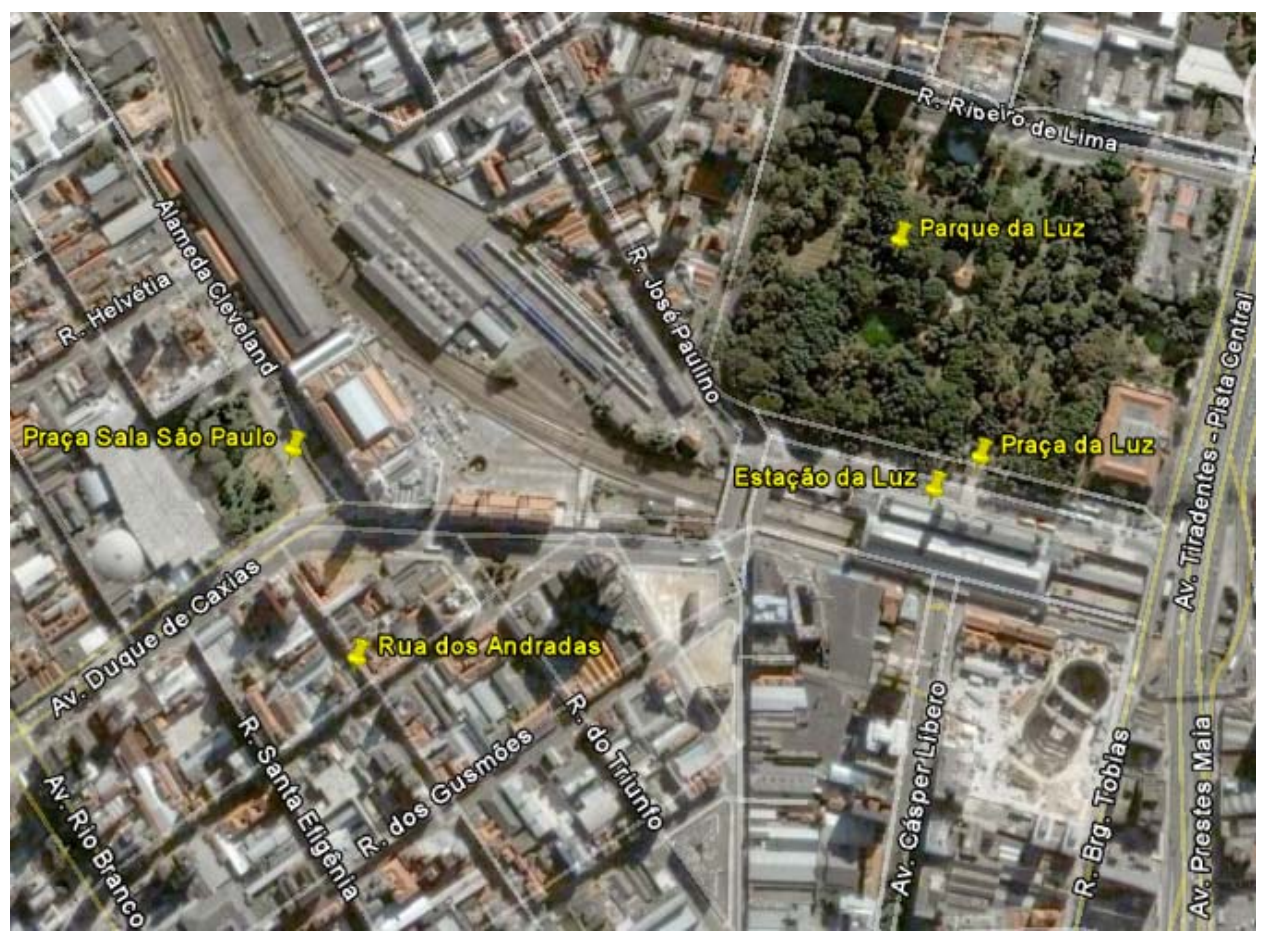

Figura 1 - Locais levantados empiricamente no Bairro da Luz
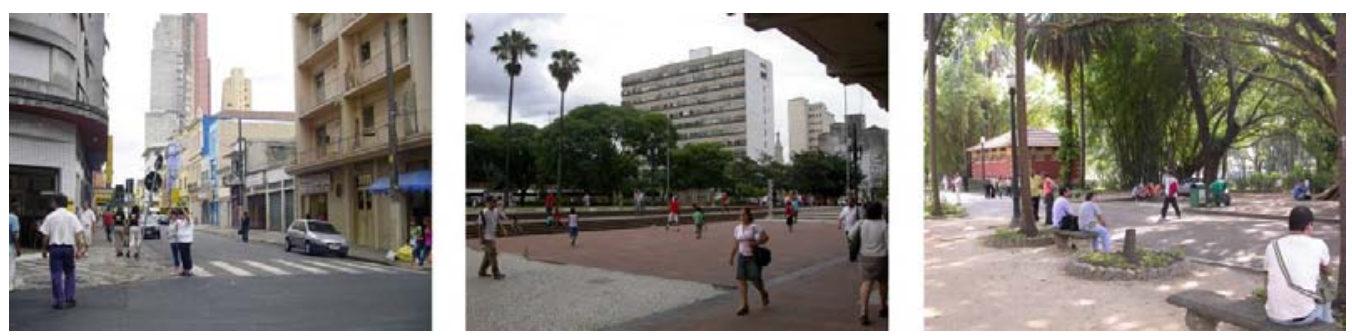

Figura 2 - Vista das bases levantadas empiricamente no verão 

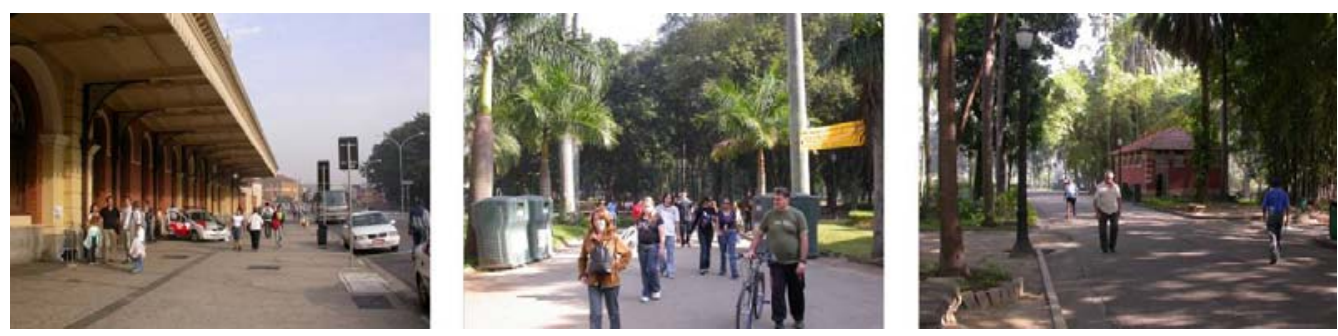

Figura 3 - Vista das bases levantadas empiricamente no inverno
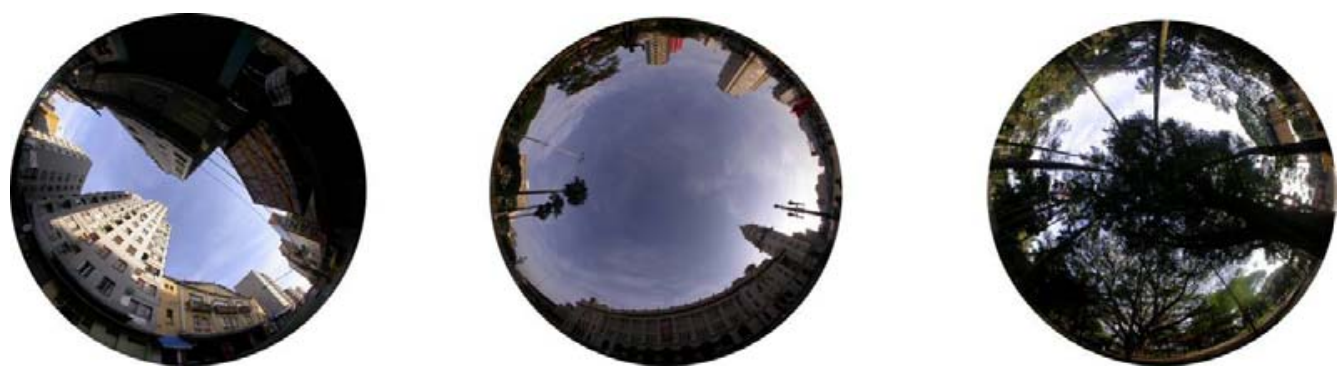

Figura 4 - Condições de exposição ao céu das bases no verão
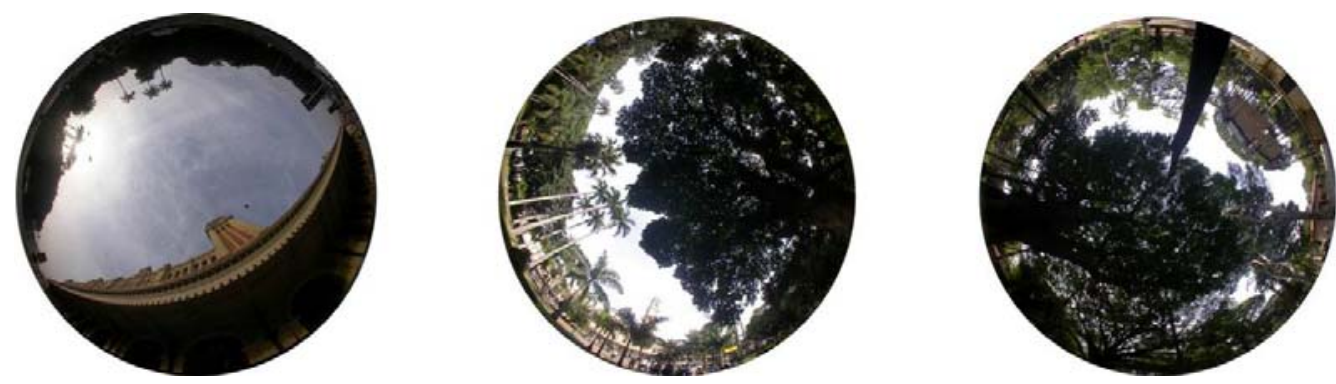

Figura 5 - Condições de exposição ao céu das bases no inverno

\begin{tabular}{|l|l|l|l|}
\hline \multicolumn{1}{|c|}{ Tipologia } & \multicolumn{1}{c|}{ Uso predominante } & \multicolumn{1}{c|}{ Verão } & \multicolumn{1}{c|}{ Inverno } \\
\hline Rua & Passagem & Rua dos Andradas & Estação da Luz \\
\hline Praça & Passagem/Permanência & Praça Sala São Paulo & Praça da Luz \\
\hline Parque & Permanência & Parque da Luz & Parque da Luz \\
\hline
\end{tabular}

Quadro 1 - Locais levantados empiricamente no Bairro da Luz

As Figuras 4 e 5 mostram as condições de exposição ao céu das bases no verão e no inverno. No verão, tem-se uma situação em cânion urbano, com baixo valor de fator de visão do céu, uma situação em praça aberta, com alto valor de fator de visão do céu, e uma situação sob copas de árvores, com baixo fator de visão do céu. Já no inverno, foram levantadas situações com valores mais baixos de fator de visão do céu. Em vez da praça a céu aberto, foi considerada situação parcialmente coberta por beiral da Estação da Luz, e ainda duas situações sob copa de árvores, com valores distintos de fator de visão do céu.

Em resumo, o Quadro 1 apresenta os locais levantados empiricamente, no verão e no inverno, e os usos predominantes.
A fim de elucidarem-se os limites de aplicabilidade das propostas a serem realizadas, as Tabelas de 1 a 3 apresentam comparativamente os valores-limite observados nos levantamentos laboratoriais na Cidade Universitária e nos levantamentos de campo no Bairro da Luz.

Ressalta-se que os valores verificados nas situações microclimáticas do Bairro da Luz estão dentro dos limites verificados para a Cidade Universitária, possibilitando, assim, a adequada verificação dos resultados obtidos com essa base empírica, uma vez que aquela base está dentro dos valores-limite desta. Ressalva deve ser feita para a temperatura do ar, que apresenta valor ligeiramente superior nos dados observados no Bairro da Luz. Poderia ter sido feita opção pela retirada dessa situação microclimática limite. 
Contudo, devido à pequena diferença encontrada, assumiu-se que a extrapolação em questão é aceitável.

Com relação aos valores do isolamento da roupa, todos os valores encontrados para o Bairro da Luz estão dentro dos limites dos encontrados na Cidade Universitária. Observa-se ainda que os limites superiores de isolamento da roupa são significativamente inferiores aos encontrados no levantamento laboratorial. Essa questão será considerada mais detidamente em item posterior, quando forem observadas as particularidades de cada variável.

Por fim, referentemente à taxa metabólica, deve-se observar que os levantamentos laboratoriais na Cidade Universitária consideraram apenas um único tipo de atividade, tendo sido as variações de taxa metabólica consideradas apenas por meio de modelos teóricos. A implicação da consideração de diferentes taxas metabólicas também será verificada.

Na sequência, serão explicitados os métodos de coleta e tratamento das variáveis apresentadas.

\section{Quantificação de variáveis}

\section{Variáveis ambientais}

As variáveis ambientais microclimáticas consideradas nesta pesquisa foram temperatura, umidade e velocidade do ar, e temperatura radiante média. Para a quantificação física das variáveis ambientais, utilizou-se a norma ISO 7726
(INTERNATIONAL..., 1998), adaptada por Monteiro (2011).

A realização da quantificação de variáveis deve levar em consideração sua homogeneidade e heterogeneidade, assim como o caráter estacionário e variacional do tempo das grandezas medidas. Consideraram-se ainda as posições utilizadas na medição das quantidades físicas e os coeficientes de ponderação usados no cálculo do valor médio dessas quantidades, seguindo a norma ISO 7726 (INTERNATIONAL..., 1998). Com base em resultados de Monteiro (2008), realizando pré-testes de medições nas três alturas recomendadas, ao longo de dias de verão e de inverno, verificou-se para diferentes tipologias distintas de espaços abertos que os ambientes ali configurados eram homogêneos, de acordo com o prescrito pela norma ISO 7726 (INTERNATIONAL..., 1998). Ressalta-se que foram verificados alguns desvios apenas ligeiramente maiores do que o especificado pela norma para as variáveis temperatura radiante média e velocidade do ar nas medições realizadas a 0,1 m. Dessa forma, nos levantamentos realizados, devido aos resultados prévios, realizaram-se medições apenas a 1,1 m de altura, uma vez que as atividades verificadas, com as pessoas sentadas ou em pé, implicavam medições apenas a $1,1 \mathrm{~m}$ e a $0,6 \mathrm{~m}$. Como se considerou que os ambientes são suficientemente homogêneos, não se fez distinção em relação à altura, tendo sido eleita a de $1,1 \mathrm{~m}$, pois a grande maioria dos usuários dos espaços exercia atividades em pé.

Tabela 1 - Valores-limite das variáveis ambientais microclimáticas

\begin{tabular}{c|c|c|c|c}
\hline \multirow{2}{*}{ variável } & \multicolumn{2}{|c|}{ Cidade Universitária } & \multicolumn{2}{c}{ Bairro da Luz } \\
\cline { 2 - 5 } & $\begin{array}{c}\text { valor mínimo } \\
\text { observado }\end{array}$ & $\begin{array}{c}\text { valor máximo } \\
\text { observado }\end{array}$ & $\begin{array}{c}\text { valor mínimo } \\
\text { observado }\end{array}$ & $\begin{array}{c}\text { valor máximo } \\
\text { observado }\end{array}$ \\
\hline $\mathrm{t}_{\mathrm{ar}}$ & 15,1 & 33,1 & 17,4 & 33,7 \\
$\mathrm{ur}$ & 31 & 95 & 35 & 85 \\
$\mathrm{v}_{\mathrm{ar}}$ & 0,1 & 3,6 & 0,1 & 2,7 \\
$\mathrm{t}_{\mathrm{rm}}$ & 15,5 & 65,5 & 17,4 & 47,8 \\
\hline
\end{tabular}

Tabela 2 - Valores-limite do isolamento da roupa, considerando valores observados e médios

\begin{tabular}{l|c|c|c|c}
\hline \multicolumn{1}{c|}{$\mathbf{I}_{\mathbf{c l}}$} & $\begin{array}{c}\text { valor mínimo } \\
\text { observado }\end{array}$ & $\begin{array}{c}\text { valor médio } \\
\text { mínimo }\end{array}$ & $\begin{array}{c}\text { valor médio } \\
\text { máximo }\end{array}$ & $\begin{array}{c}\text { valor máximo } \\
\text { observado }\end{array}$ \\
\hline Cidade Universitária & 0,26 & 0,39 & 0,86 & 1,17 \\
Bairro da Luz & 0,30 & 0,41 & 0,66 & 0,90 \\
\hline
\end{tabular}

Tabela 3 - Valores-limite da taxa metabólica, considerando valores observados e médios

\begin{tabular}{l|c|c|c|c}
\hline \multicolumn{1}{c|}{$\mathbf{M}_{\mathrm{et}}$} & $\begin{array}{c}\text { valor mínimo } \\
\text { observado }\end{array}$ & $\begin{array}{c}\text { valor médio } \\
\text { mínimo }\end{array}$ & $\begin{array}{c}\text { valor médio } \\
\text { máximo }\end{array}$ & $\begin{array}{c}\text { valor máximo } \\
\text { observado }\end{array}$ \\
\hline Cidade Universitária & 1,3 & 1,3 & 1,3 & 1,3 \\
Bairro da Luz & 1,0 & 1,2 & 2,5 & 5,8 \\
\hline
\end{tabular}

66 Monteiro, L. M.; Alucci, M. P. 
Com relação aos sensores para quantificação física, para determinação da temperatura do ar foram utilizados sensores do tipo semicondutor. A faixa de leitura é de $-20{ }^{\circ} \mathrm{C}$ a $+60{ }^{\circ} \mathrm{C}$, com resolução de $0,1{ }^{\circ} \mathrm{C}$, precisão de $\pm 0,4{ }^{\circ} \mathrm{C}$, e tempo de resposta de $0,1{ }^{\circ} \mathrm{C} / \mathrm{s}$. Para a obtenção da umidade relativa, foram empregados sensores de capacitância. A faixa de leitura é de $10 \%$ a $95 \%$, com resolução de $0,1 \%$, precisão de $\pm 3 \%$ (a $25^{\circ} \mathrm{C}$, entre $30 \%$ e $95 \%$ ) e $\pm 5 \%$ (a $25{ }^{\circ} \mathrm{C}$, entre $10 \%$ e $30 \%$ ), e tempo de resposta de 3 min para mudança de $45 \%$ a $95 \%$, e de $5 \mathrm{~min}$ para o inverso. Quanto à velocidade do vento, utilizaram-se sensores de velocidade do ar compostos de copo (magnitude) e pá (direção/sentido), apresentando faixa de leitura de $0,3 \mathrm{~m} / \mathrm{s}$ a $30,0 \mathrm{~m} / \mathrm{s}$, resolução de $0,1 \mathrm{~m} / \mathrm{s}$ e precisão de $\pm 2 \%+\mathrm{d}$.

Por fim, com relação à temperatura radiante média, essa foi estimada a partir de medições de temperatura de globo, tendo sido utilizados globos de $10 \mathrm{~cm}$ de diâmetro, preto fosco e cinza médio fosco, com emissividade de aproximadamente 0,95 . Para determinação da temperatura do ar no centro do globo, foram utilizados sensores do tipo semicondutor, com faixa de leitura de $-20{ }^{\circ} \mathrm{C}$ a +60 ${ }^{\circ} \mathrm{C}$, resolução de $0,1{ }^{\circ} \mathrm{C}$, precisão de $\pm 0,4{ }^{\circ} \mathrm{C}$, e tempo de resposta de $0,1{ }^{\circ} \mathrm{C} / \mathrm{s}$. Com relação ao desempenho do sistema, segundo a ISO 7726 (INTERNATIONAL..., 1998), o tempo de resposta de um termômetro de globo é de aproximadamente $20 \mathrm{~min}$ a $30 \mathrm{~min}$, dependendo das características do globo e do ambiente em avaliação. Considerando-se as quantificações físicas das variáveis anteriormente elencadas, para o cálculo da temperatura radiante média, realiza-se o balanço das trocas térmicas entre o globo e o ambiente em questão, considerando-se a temperatura do ar no centro do globo, a temperatura e a velocidade do ar no ambiente. Como resultado, têm-se as formulações para convecção natural e convecção forçada (INTERNATIONAL..., 1998).

\section{Variáveis individuais}

As variáveis individuais levantadas na pesquisa empírica foram taxa metabólica e resistência térmica da roupa. Além da estimativa desses valores, consideraram-se o trabalho mecânico e a resistência evaporativa da roupa, associados respectivamente à taxa metabólica e à resistência térmica da roupa. Na sequência, apresentam-se os critérios utilizados, seguidos dos métodos e procedimentos empregados.

Tomando-se como referência os valores de taxa metabólica apresentados pela ISO 8996 (INTERNATIONAL..., 1990), e observando as atividades realizadas pelas pessoas ao longo dos pré-testes realizados nos locais dos levantamentos empíricos, determinaram-se valores para as taxas metabólicas em função das atividades observadas. Quando da aplicação do questionário de avaliação subjetiva das condições térmicas ambientais, o entrevistador tomava nota da atividade que a pessoa estava exercendo. Devido a observações feitas nos pré-testes (considerando-se o consumo de oxigênio, o equivalente energético e a área de DuBois), simplificou-se a anotação da atividade, utilizando-se apenas quatro valores referenciais. Dessa forma, os levantamentos consideram grupos de dados referentes a atividades metabólicas médias de 1,0, 1,3, 2,0 e 5,8 Met. Com relação à eficiência mecânica, devido às atividades verificadas, ela é desprezível.

Com relação aos valores de isolamento térmico, da resistência evaporativa e do fator de roupa, utilizou-se a escala da Figura 6, para que se tomasse nota das vestimentas que o entrevistado estava usando. As imagens da figura foram adaptadas da ISO 9920 (INTERNATIONAL..., 1995), em que cada peça de roupa está associada a um fator de roupa. Consideraram-se os valores tabelados de resistência térmica da roupa, adaptados da ISO 9920 (INTERNATIONAL..., 1995), e as relações entre estes e a resistência evaporativa das roupas e os fatores de roupa. Assim, os valores apresentados na figura já fazem referência ao isolamento térmico estimado em clo, tendo sido a resistência evaporativa da roupa e o fator de roupa calculados conforme as formulações normativas.

\section{Variáveis subjetivas}

As variáveis subjetivas quantificadas nesta pesquisa dizem respeito à percepção de sensação térmica e conforto térmico. O levantamento baseou-se nos princípios estabelecidos pela norma ISO 10551 (INTERNATIONAL..., 1995).
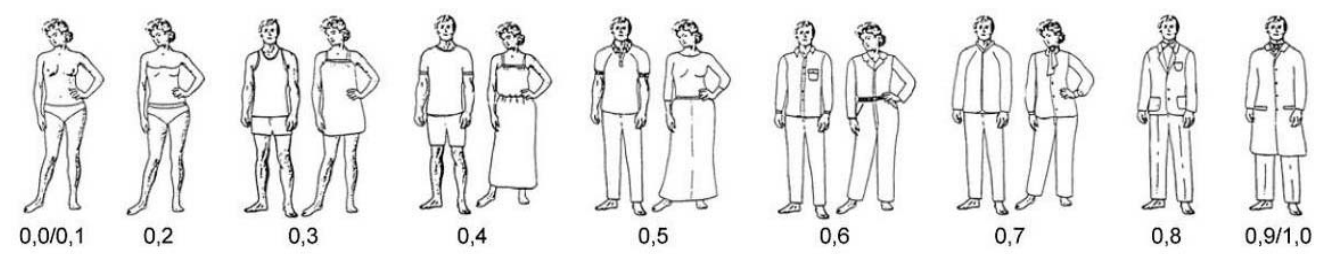

Figura 6 - Isolamento térmico estimado em clo 
Após a realização de pré-testes com diversos modelos de questionários, utilizando-se diferentes abordagens para a realização das perguntas, optouse pelo modelo da Figura 7. Para a quantificação das variáveis subjetivas de percepção foram estabelecidas duas questões, uma para verificação de sensação térmica e outra para a de conforto térmico. Dependendo das respostas, havia uma segunda questão, subsequente a cada uma delas. Para verificar a sensação térmica, a primeira questão realizada pelo entrevistador era por meio da pergunta "Neste momento, aqui, você está com frio, calor ou nenhum dos dois?". Se o entrevistado respondesse "frio" ou "calor", havia então a segunda questão: "Você está com pouco calor (frio), mais ou menos, ou muito calor (frio)?”. Para verificar o conforto térmico, o entrevistador repetia a resposta da pessoa da(s) questão(ões) anterior(es), perguntando: "Com relação a esse pouco calor (muito frio, neutralidade, etc.), você está confortável ou desconfortável?". Se o entrevistado respondesse "desconfortável", havia então uma segunda pergunta: "Você está pouco, mais ou menos ou muito desconfortável?".

Para a anotação das respostas, foram utilizados os critérios de ponto central e escalas de intensidades positivas e/ou negativas, quando aplicáveis. As questões de percepção de sensação térmica e de conforto térmico foram, cada uma delas, desmembradas em duas questões subsequentes e dependentes, pois, dessa forma, se facilitava a aplicação do questionário. Assim, a primeira pergunta possibilita uma resposta com valor positivo, negativo ou igual a zero. A segunda pergunta possibilita, caso a primeira pergunta apresente valor positivo ou negativo, a quantificação desse valor, "1", “2” ou "3”, respectivamente representando "pouco", "mais ou menos" e "muito".

\section{Outras variáveis}

Devido às características específicas já elencadas dos levantamentos de campo, realizaram-se simplificações acerca da verificação da aclimatação, perguntando apenas a cidade/estado em que nasceu e há quanto tempo está na região metropolitana de São Paulo. Com relação às informações pessoais, essas não foram questionadas, mas sim estimadas pelos entrevistadores (que receberam treinamento prévio para tanto), conforme a Figura 6.

Ressalta-se que o número de perguntas é pequeno, restrito de quatro a seis, dependendo das respostas das pessoas, e que as perguntas são extremamente objetivas, sendo as respostas ou repetições de parte das perguntas ou informações muito fáceis de ser fornecidas. Assim, a realização inicial de uma explicação ou solicitação de autorização mostrouse, nos pré-testes, inibidora ou demandante de tempo consideravelmente longo, tendo sido, por isso, descartada nos levantamentos efetivos.

\section{Variáveis adaptativas}

Descrevem-se na sequência os métodos empregados para a avaliação das variáveis taxa metabólica, isolamento térmico da roupa $\mathrm{e}$ temperatura média mensal.

Para tanto, é considerada a proposição da equação que fornece valores de temperatura equivalente percebida (TEP), considerando-se que a TEP de um dado ambiente pode ser sucintamente definida como uma escala de sensação térmica que apresenta valores numericamente iguais aos da temperatura do ar de um ambiente de referência (tar $=$ trm, $u r=50 \%$ e var $=0$ ) em que se verifica o mesmo valor médio de percepção de sensação térmica que no ambiente em questão. Baseando-se nessas assunções, a relação entre a TEP e as sensações térmicas (Sens, escala convencional de \pm 3 ) pela equação determinada com a base empírica levantada na Cidade Universitária é a seguinte(Equação 1).

$\mathrm{TEP}=23,395+7,639 \cdot$ Sens

Eq. 1

Nos subitens a seguir, são verificadas as variáveis citadas (taxa metabólica, isolamento térmico da roupa e temperatura média mensal), por meio do índice de TEP, confrontando os resultados da base empírica levantada na Cidade Universitária com os resultados empíricos levantados no Bairro da Luz.

\begin{tabular}{|l|l|l|l|l|}
\hline & $\begin{array}{l}\text { Sens } \\
-3 \sim 3\end{array}$ & $\begin{array}{l}\text { Conf } \\
0 \sim 3\end{array}$ & $\begin{array}{l}\text { Nascimento } \\
\text { Cidade/Estado }\end{array}$ & $\begin{array}{l}\text { Tempo vivendo } \\
\text { na Grande SP }\end{array}$ \\
\hline 01 & & & & \\
\hline 02 & & & & \\
\hline
\end{tabular}

\begin{tabular}{|l|l|l|l|l|l|l|}
\hline $\begin{array}{l}\text { Iclo } \\
0,3 \sim 0,9\end{array}$ & $\begin{array}{l}\text { Cor } \\
\text { CME }\end{array}$ & $\begin{array}{l}\text { Idade } \\
\text { Aprox }\end{array}$ & $\begin{array}{l}\text { Sexo } \\
\mathrm{M} / \mathrm{F}\end{array}$ & $\begin{array}{l}\text { Ativ } \\
0 \sim 3\end{array}$ & $\begin{array}{l}\text { Sol? } \\
\mathrm{S} / \mathrm{N}\end{array}$ & $\begin{array}{l}\text { Horário } \\
\text { hh:mm }\end{array}$ \\
\hline & & & & & & \\
\hline & & & & & & \\
\hline
\end{tabular}

Figura 7 - Cabeçalho para preenchimento das respostas às questões e das variáveis observadas 


\section{Taxa metabólica}

Para a verificação da alteração das taxas metabólicas na TEP, Monteiro e Alucci (2009b) descrevem simulações por meio de modelagem adaptada a partir de Blazejczyk (1996), Vogt et al. (1981) e Dominguez et al. (1992). Foi considerada toda a faixa de aplicação do índice TEP compreendida entre os seus valores-limite:

$$
\begin{aligned}
& \mathrm{T}_{\mathrm{ar}}=15 \sim 33{ }^{\circ} \mathrm{C} ; \\
& \mathrm{t}_{\mathrm{rm}}=15 \sim 66^{\circ} \mathrm{C} ; \\
& \mathrm{ur}=30 \sim 90 \% ; \\
& \mathrm{v}_{\mathrm{ar}}=0,1 \sim 3,6 \mathrm{~m} / \mathrm{s} ; \mathrm{e} \\
& \mathrm{I}_{\mathrm{cl}}=0,25-1,25 \text { clo. }
\end{aligned}
$$

Foram feitas simulações com incrementos de $t_{a r}=3$ ${ }^{\circ} \mathrm{C} ; \mathrm{t}_{\mathrm{rm}}=6{ }^{\circ} \mathrm{C} ; \mathrm{ur}=15 \% ; \mathrm{v}_{\mathrm{ar}}=0,5 \mathrm{~m} / \mathrm{s}$ e $\mathrm{I}_{\mathrm{cl}}=0,25 \mathrm{clo}$. Os seguintes ajustes foram feitos: para trm considerou-se até o valor de $69{ }^{\circ} \mathrm{C}$; para ur iniciouse em $35 \%$ e finalizou-se em $90 \%$; e para $I_{c l}$ iniciou-se em 0,25 clo e finalizou-se em 1,25 clo, garantindo-se a integridade dos intervalos. Garantiu-se ainda a coincidência com os valores da $\mathrm{t}_{\mathrm{ar}}$, no caso da $\mathrm{tr}_{\mathrm{m}}$, e com os valores comumente empregados, no caso da ur $(30 \%, 45 \%, 60 \%, 75 \%$ e $90 \%)$ e do $I_{c l}(0,25 ; 0,5 ; 0,75 ; 1,0 ; 1,25)$. Realizando-se todas as possibilidades combinatórias dessas variáveis ( 7 valores de $t_{\mathrm{ar}}, 10$ de $\mathrm{t}_{\mathrm{rm}}, 5$ de ur, 8 de $\mathrm{v}_{\mathrm{ar}}$ e $\left.5 \mathrm{de}^{\mathrm{cl}}\right)$, totalizaram-se 14.000 simulações $(7 \times 10 \times 5 \times 8 \times 5)$ para cada taxa metabólica, determinando os valores teóricos de TEP que proporcionam a mesma sensação térmica em diferentes atividades.

Os valores encontrados nas simulações são apresentados na Tabela 4. Observando-a, para taxas metabólicas de 1,0 e 2,0 Met, o erro estimado é igual ou menor a $0,1{ }^{\circ} \mathrm{C}$. Para 2,4 Met, o erro estimado é da ordem de $0,5^{\circ} \mathrm{C}$. Nos casos de taxas metabólicas mais elevadas, verifica-se que os erros estimados são crescentes, mesmo em faixas de aplicabilidade mais restritas.

Considerando-se que para a atividade metabólica de 2,4 Met o erro estimado de $0,5{ }^{\circ} \mathrm{C}$ seja aceitável, propôs-se a seguinte linearização (regressão linear) dos valores encontrados para atividade entre 0,0 e 2,4 Met (Equação 2).

$\Delta \mathrm{TEP}=-6,648+5,118 \cdot \mathrm{M}$

Eq. 2

Onde:

$\Delta \mathrm{TEP}=$ variação na temperatura equivalente percebida, em ${ }^{\circ} \mathrm{C}$.

Para a faixa de valores proposta, a equação apresenta correlação de 1 , portanto com $r^{2}$ também igual 1 , e $\mathrm{r}^{2}$ ajustado de 0,999 . O erro padrão é 0,080, e a significância, de $\mathrm{p}<0,001$. Em termos práticos, a linearização proposta mantém a correção dos valores compreendidos entre 1,0 e 2,0 Met. Para o valor de 2,4 Met, a equação prediz um valor de $5,6{ }^{\circ} \mathrm{C}$, quando o correto seria $5,7{ }^{\circ} \mathrm{C}$. Como o erro estimado para os resultados dessa taxa metabólica já era de $0,5^{\circ} \mathrm{C}$, o maior erro acumulado teórico seria de $0,6^{\circ} \mathrm{C}$.

\section{Resultados parciais da variável taxa metabólica}

De forma sucinta, seguindo os resultados das simulações, e a consequente formulação obtida por regressão linear dos resultados, apresenta-se a Tabela 5 com os valores referenciais de taxas metabólicas para utilização no cálculo de TEP, para as atividades físicas levantadas no Bairro da Luz.

\section{Tabela 4 - Resumo dos resultados das simulações para determinação da TEP em função de diferentes} taxas metabólicas

\begin{tabular}{l|c|c|c|c|c|c|c}
\hline & Sentado & Em pé & \multicolumn{5}{c}{ Andando } \\
\hline velocidade da pessoa $(\mathrm{m} / \mathrm{s})$ & - & - & 0,9 & 1,1 & 1,3 & 1,5 & 1,7 \\
velocidade da pessoa $(\mathrm{km} / \mathrm{h})$ & - & - & 3,2 & 4 & 4,7 & 5,4 & 6,1 \\
taxa metabólica $(\mathrm{Met})$ & 1 & 1,3 & 2,0 & 2,4 & 2,6 & 3,0 & 3,5 \\
TEP consideradas $\left({ }^{\circ} \mathrm{C}\right)$ & $12 \sim 45$ & $12 \sim 45$ & $12 \sim 39$ & $12 \sim 39$ & $15 \sim 36$ & $15-36$ & $15 \sim 36$ \\
correção $\left({ }^{\circ} \mathrm{C}\right)$ & $-1,5$ & 0,0 & 3,5 & 5,7 & 7,7 & 13,5 & 20,4 \\
erro estimado $\left({ }^{\circ} \mathrm{C}\right)$ & $\pm 0,0$ & $\pm 0,0$ & $\pm 0,1$ & $\pm 0,5$ & $\pm 0,8$ & $\pm 2,0$ & $\pm 3,3$ \\
\hline
\end{tabular}

Tabela 5 - Valores referenciais de taxas metabólicas para utilização no cálculo de TEP

\begin{tabular}{l|c|c|c}
\hline \multicolumn{1}{c|}{ Atividade } & Taxa metabólica (Met) & $\Delta$ TEP $\left({ }^{\circ} \mathbf{C}\right)$ & $\Delta$ Sens \\
\hline Sentado & 1,0 & $-1,5$ & $-0,20$ \\
Em pé, com pouca atividade & 1,3 & 0,0 & 0,00 \\
Locomovendo-se lentamente & 1,6 & 1,5 & 0,20 \\
Andando relaxadamente $(3,2 \mathrm{~km} / \mathrm{h})$ & 2,0 & 3,5 & 0,46 \\
Caminhando normalmente $(4,0 \mathrm{~km} / \mathrm{h})$ & 2,4 & 5,7 & 0,75 \\
Correndo $(8,0 \mathrm{~km} / \mathrm{h})$ & 5,8 & $*$ & $*$ \\
\hline
\end{tabular}

Nota: *valores não definidos por meio das simulações computacionais. 
Os valores da variação de percepção de sensação térmica $(\Delta$ Sens $)$ foram definidos conforme se segue (Equação 3).

$\Delta$ Sens $=0,1309 \cdot \Delta$ TEP

Eq. 3

Essas considerações, relativas à variação de percepção de sensação térmica em função das simulações computacionais realizadas, são verificadas aqui ante os dados levantados no Bairro da Luz. Considerando os 859 conjuntos de dados levantados (amostra total de questionários válidos), apenas $14(1,6 \%)$ dizem respeito a situações de pessoas correndo, em que se tem atividade física de 5,8 Met. Assim, uma vez que essa taxa metabólica não foi prevista pelo modelo recém-apresentado, e apresenta uma amostra muito pequena, não será considerada nesta verificação. Dos conjuntos de dados restantes, $83(10,1 \%)$ dizem respeito a pessoas sentadas (1,0 Met), 145 $(16,9 \%)$ a pessoas em pé $(1,3 \mathrm{Met})$, e $613(71,4 \%)$ a pessoas andando (de 1,6 a 2,4 Met, em média 2,0 Met).
Os resultados desses tipos de atividade física ponderados levando-se em consideração o número de observações verificadas em cada uma das quarenta e quatro situações microclimáticas no Bairro da Luz, são apresentados na Tabela 6 a seguir.

Considerando os resultados apresentados na Tabela 6 e a relação entre a variação na percepção de sensação térmica e a variação na temperatura equivalente percebida, verifica-se a seguinte regressão linear simples (Equação 4), $\mathrm{r}^{2}=0,9996$, considerando-se que a temperatura equivalente percebida de referência é a observada para a atividade em que as pessoas estão em pé e paradas.

$$
\Delta \mathrm{TEP}=-3,121+2,405 \cdot \mathrm{M} \quad \text { Eq. } 4
$$

A Figura 8 a seguir apresenta, comparativamente, a variação na temperatura equivalente percebida prevista pelas simulações computacionais e a observada em campo.

A Tabela 7 a seguir reapresenta as situações inicialmente consideradas, com os valores verificados em campo.

Tabela 6 - Resultados médios de sensação térmica (Sens média) por taxa metabólica (Met)

\begin{tabular}{l|l|c|c|c|c|c}
\hline Atividade & $\begin{array}{c}\text { Taxa } \\
\text { metabólica } \\
\text { (Met) }\end{array}$ & $\begin{array}{c}\Delta \text { Sens } \\
\text { prevista }\end{array}$ & $\begin{array}{c}\text { Sens } \\
\text { média }\end{array}$ & $\begin{array}{c}\text { Desvio } \\
\text { padrão }\end{array}$ & $\begin{array}{c}\Delta \text { Sens } \\
\text { verificada }\end{array}$ \\
\hline 0 & Sentado & 1,0 & $-0,20$ & 0,86 & $\pm 1,13$ & $-0,09$ \\
1 & Em pé & 1,3 & 0,00 & 0,97 & $\pm 1,29$ & 0,00 \\
2 & Andando & 2,0 & 0,46 & 1,19 & $\pm 1,43$ & 0,22 \\
\hline
\end{tabular}

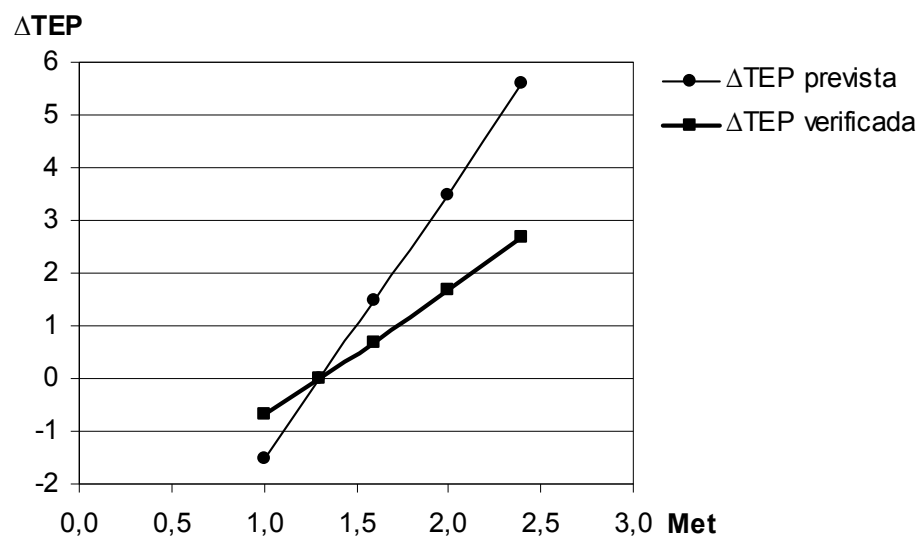

Figura 8 - $\triangle$ TEP prevista e verificada em função da taxa metabólica

Tabela 7 - Novos valores referenciais de taxas metabólicas para utilização no cálculo de TEP

\begin{tabular}{l|c|c|c}
\hline \multicolumn{1}{c|}{ Atividade } & Taxa metabólica (Met) & $\Delta$ TEP $\left({ }^{\circ} \mathbf{C}\right)$ & $\Delta$ Sens \\
\hline Sentado & 1,0 & $-0,7$ & $-0,09$ \\
Em pé, com pouca atividade & 1,3 & 0 & 0 \\
Locomovendo-se lentamente & 1,6 & 0,7 & 0,09 \\
Andando relaxadamente $(3,2 \mathrm{~km} / \mathrm{h})$ & 2,0 & 1,7 & 0,22 \\
Caminhando normalmente $(4,0 \mathrm{~km} / \mathrm{h})$ & 2,4 & 2,7 & 0,35 \\
\hline
\end{tabular}

70 Monteiro, L. M.; Alucci, M. P. 


\section{Conclusão acerca dos resultados da variável taxa metabólica}

Pode-se verificar que a variação na percepção de sensação térmica e, consequentemente, a variação da temperatura equivalente percebida são consideravelmente menores do que o previsto nas simulações, sendo sempre inferior à metade do valor previsto. Essa verificação é passível de um maior número de observações e, ainda, em outras situações ambientais. Contudo, dentro dos limites em que ela foi realizada, pode-se depreender que a taxa metabólica não é simplesmente uma variável a ser considerada no resultado final das condições microclimáticas, mas, sim, variável determinada por essas próprias condições. Assim, considerando que por meio da realização de diferentes atividades as pessoas têm possibilidade de adaptar-se em espaços abertos urbanos, os resultados encontrados não são conclusivos, e outros levantamentos empíricos são necessários para quantificar-se adequadamente a capacidade adaptativa específica.

\section{Isolamento térmico da roupa}

Monteiro e Alucci (2009b), para a determinação de um modelo para estimativa do isolamento da roupa, com base nos dados empíricos levantados na Cidade Universitária, após apresentarem diversas modelagens, consideram a seguinte (Equação 5), por apresentar correlação mais significativa (resumo estatístico e análise de variância, respectivamente, nas Tabelas 8 e 9).

$\mathrm{I}_{\mathrm{cl}}=1,203-0,0263 \cdot \mathrm{t}_{\mathrm{ar}}$

Eq. 5

Onde:

$\mathrm{r}=0,832$; $\mathrm{r}^{2}=0,691$;

$\mathrm{r}^{2} \mathrm{aj}=0,687$;

ep $=0,067$; e

$\mathrm{p}<0,001$.

Considerando os resultados previstos pela equação, caso não houvesse restrições culturais, poderia ser adotado o limite, ainda que teórico, de $45,7{ }^{\circ} \mathrm{C}$, no qual se teria $\mathrm{I}_{\mathrm{cl}}=0,00$ clo. Considerando-se trajes de banho, para $\mathrm{t}_{\mathrm{ar}}>44,0$ ${ }^{\circ} \mathrm{C}$, tem-se $\mathrm{I}_{\mathrm{cl}}=0,05$ clo. Contudo, grosso modo, pode-se colocar que, em situações gerais em espaços abertos, para $\mathrm{t}_{\mathrm{ar}}>30,0^{\circ} \mathrm{C}$, tem-se $\mathrm{I}_{\mathrm{cl}}=$ 0,40 clo. Caso se considere a limitação de vestimentas comumente utilizadas em atividades de escritório (calça social, camisa de manga curta, sapatos, meias e roupa íntima), verifica-se que, para $t_{\mathrm{ar}}>26,5{ }^{\circ} \mathrm{C}$, tem-se $\mathrm{I}_{\mathrm{cl}}=0,50$ clo. Assim, para aplicações práticas do modelo proposto, a Tabela 10 a seguir apresenta esquematicamente esses limites.

Nos levantamentos realizados nesta pesquisa no Bairro da Luz, pode-se considerar o valor-limite para vestimentas comumente usadas em espaços urbanos, ainda que se tenha observado valores individuais abaixo desse limite.

\section{Resultados parciais da variável isolamento térmico da roupa}

A Tabela 11 a seguir apresenta de forma esquemática os valores previstos, em função da temperatura do ar, e observados de isolamento térmico da roupa para diversas situações microclimáticas levantadas no Bairro da Luz.

Tabela 8 - Resumo estatístico da constante e da variável independente

\begin{tabular}{l|r|c|c|c|c}
\hline & c & ep & t & p & VIF \\
\hline Constante & 1,203 & 0,0515 & 23,373 & $<0,001$ & \\
$\mathrm{t}_{\mathrm{ar}}$ & $-0,026$ & 0,0021 & $-12,53$ & $<0,001$ & - \\
\hline
\end{tabular}

Tabela 9 - Análise de variância

\begin{tabular}{l|r|c|c|c|c}
\hline & DF & SS & MS & F & p \\
\hline Regressão & 1 & 0,711 & 0,7110 & 156,87 & $<0,001$ \\
Resíduo & 70 & 0,317 & 0,0045 & & \\
Total & 71 & 1,028 & 0,0145 & & \\
\hline
\end{tabular}

Tabela 10 - Valores-limite da variável isolamento da roupa, segundo critérios físicos e culturais

\begin{tabular}{l|c|c}
\hline \multicolumn{1}{c|}{ Limite } & $\mathbf{T}_{\mathbf{a r}}$ & $\mathbf{I}_{\mathbf{c l}}$ \\
\hline Físico teórico & $>45,7^{\circ} \mathrm{C}$ & 0,00 \\
Para trajes de banho & $>44,0^{\circ} \mathrm{C}$ & 0,05 \\
Para vestimentas usadas em espaços urbanos & $>30,0^{\circ} \mathrm{C}$ & 0,40 \\
Para vestimentas usadas em escritório & $>26,5^{\circ} \mathrm{C}$ & 0,50 \\
\hline
\end{tabular}


Tabela 11 - Isolamento térmico da roupa previsto e observado para as situações ambientais levantadas empiricamente

\begin{tabular}{|c|c|c|c|c|c|}
\hline Estação & Local & Horário & Ta & Icl previsto & Icl observado \\
\hline \multirow[t]{14}{*}{ Verão } & \multirow[t]{5}{*}{ Rua } & $07 \mathrm{~h} 00$ & 23,3 & 0,59 & 0,50 \\
\hline & & $10 \mathrm{~h} 00$ & 29,1 & 0,44 & 0,48 \\
\hline & & $13 \mathrm{~h} 00$ & 30,2 & 0,41 & 0,46 \\
\hline & & $16 \mathrm{~h} 00$ & 33,7 & 0,40 & 0,49 \\
\hline & & $19 \mathrm{~h} 00$ & 29,7 & 0,42 & 0,47 \\
\hline & \multirow[t]{5}{*}{ Praça } & $07 \mathrm{~h} 00$ & 22,4 & 0,61 & 0,47 \\
\hline & & $10 \mathrm{~h} 00$ & 32,3 & 0,40 & 0,47 \\
\hline & & $13 \mathrm{~h} 00$ & 32,0 & 0,40 & 0,45 \\
\hline & & $16 \mathrm{~h} 00$ & 34,3 & 0,40 & 0,47 \\
\hline & & 19h00 & 30,1 & 0,41 & 0,44 \\
\hline & \multirow[t]{4}{*}{ Parque } & $07 \mathrm{~h} 00$ & 21,6 & 0,64 & 0,41 \\
\hline & & $10 \mathrm{~h} 00$ & 26,5 & 0,51 & 0,42 \\
\hline & & $13 \mathrm{~h} 00$ & 29,5 & 0,43 & 0,45 \\
\hline & & $16 \mathrm{~h} 00$ & 32,7 & 0,40 & 0,45 \\
\hline \multirow[t]{12}{*}{ Inverno } & \multirow[t]{4}{*}{ Rua } & $07 \mathrm{~h} 00$ & 17,8 & 0,74 & 0,55 \\
\hline & & $10 \mathrm{~h} 00$ & 23,6 & 0,58 & 0,49 \\
\hline & & $13 \mathrm{~h} 00$ & 27,6 & 0,48 & 0,48 \\
\hline & & $16 \mathrm{~h} 00$ & 22,9 & 0,60 & 0,50 \\
\hline & \multirow[t]{4}{*}{ Praça } & $07 \mathrm{~h} 00$ & 17,6 & 0,74 & 0,50 \\
\hline & & $10 \mathrm{~h} 00$ & 23,4 & 0,59 & 0,50 \\
\hline & & $13 \mathrm{~h} 00$ & 27,0 & 0,49 & 0,49 \\
\hline & & $16 \mathrm{~h} 00$ & 21,5 & 0,64 & 0,52 \\
\hline & \multirow[t]{4}{*}{ Parque } & $07 \mathrm{~h} 00$ & 17,4 & 0,75 & 0,50 \\
\hline & & $10 \mathrm{~h} 00$ & 22,9 & 0,60 & 0,45 \\
\hline & & $13 \mathrm{~h} 00$ & 26,6 & 0,50 & 0,47 \\
\hline & & $16 \mathrm{~h} 00$ & 21,1 & 0,65 & 0,50 \\
\hline
\end{tabular}

Tabela 12 - Isolamento térmico da roupa previsto e observado para diferentes horários

\begin{tabular}{l|c|c|c|c}
\hline Estação & Horário & Ta & Icl previsto & Icl observado \\
\hline Verão & $07 \mathrm{~h} 00$ & 22,4 & 0,61 & 0,46 \\
& $10 \mathrm{~h} 00$ & 29,3 & 0,43 & 0,46 \\
& $13 \mathrm{~h} 00$ & 30,5 & 0,40 & 0,45 \\
& $16 \mathrm{~h} 00$ & 33,5 & 0,40 & 0,47 \\
Inverno & $19 \mathrm{~h} 00$ & 29,9 & 0,42 & 0,45 \\
& $07 \mathrm{~h} 00$ & 17,6 & 0,74 & 0,52 \\
& $10 \mathrm{~h} 00$ & 23,3 & 0,59 & 0,48 \\
& $13 \mathrm{~h} 00$ & 27,1 & 0,49 & 0,48 \\
& $16 \mathrm{~h} 00$ & 21,8 & 0,63 & 0,51 \\
\hline
\end{tabular}

Considerando os dados da Tabela 11, verifica-se correlação de $0,5(p<0,01)$ entre o isolamento da roupa previsto e o isolamento da roupa observado. Nota-se que, para as condições de verão, o valor mínimo médio observado é de 0,41 e que o valor máximo médio observado é de 0,50. Para o inverno, tem-se respectivamente 0,45 e 0,55 . Ressalta-se que, se considerados apenas os dados de verão, ou apenas os dados de inverno, em ambos os casos há correlações não significativas $(\mathrm{p}>0,05)$. Isso se deve ao fato de que variações na temperatura do ar não são acompanhadas por respectivas alterações no isolamento térmico da roupa, uma vez que há limites na capacidade adaptativa ao longo de um único dia. A Tabela 12 a seguir apresenta resumo dos valores médios por horário, para verão e inverno.

Observa-se que os resultados médios observados para verão são de $0,46 \pm 0,1$ e para inverno são de $0,50 \pm 0,2$, mostrando em ambos os casos variação menor do que a prevista em função da temperatura do ar. Considerando que a capacidade adaptativa é maior se consideradas temperaturas do ar distintas para situações distintas, a Tabela 13 a seguir apresenta os resultados para as temperaturas médias do ar ao longo do período levantado para as três situações tipológicas. 
Tabela 13 - Isolamento térmico da roupa previsto e observado para diferentes tipologias

\begin{tabular}{l|c|c|c|c}
\hline Estação & Local & Ta & Icl previsto & Icl observado \\
\hline Verão & Rua & 29,2 & 0,44 & 0,48 \\
& Praça & 30,2 & 0,41 & 0,46 \\
& Parque & 27,6 & 0,48 & 0,43 \\
& Média & 29,1 & 0,44 & 0,46 \\
Inverno & Rua & 23,0 & 0,60 & 0,50 \\
& Praça & 22,4 & 0,61 & 0,50 \\
& Parque & 22,0 & 0,62 & 0,48 \\
& Média & 22,5 & 0,61 & 0,50 \\
\hline
\end{tabular}

Verifica-se que, em função da temperatura do ar média do período, há previsões não acertadas. $\mathrm{O}$ isolamento térmico da roupa aparentemente está mais relacionado com a tipologia e os usos de cada local. Verifica-se variação maior no período do verão, em que se tem maior isolamento térmico da roupa no caso da rua, onde parte das pessoas tem restrição de uso da roupa devido a atividades de trabalho $(\mathrm{Icl} \geq 0,50)$. O menor isolamento térmico da roupa verifica-se no caso do parque, onde a grande maioria das pessoas não apresenta tal restrição. O caso da praça, com uso misto de passagem e permanência, apresenta resultado intermediário. No caso de inverno, as diferenças são menos acentuadas, notando-se apenas valor ligeiramente menor no caso do parque. Observa-se ainda que a previsão geral para verão apresenta subestimação de apenas 0,02 clo, enquanto a previsão de inverno apresenta superestimação de 0,11 clo.

\section{Conclusão acerca dos resultados da variável isolamento térmico da roupa}

A previsão do isolamento térmico da roupa, considerando as situações ambientais levantadas e os valores médios encontrados, apresenta alguma correlação $\quad\left(\mathrm{r}^{2}=0,5\right) \quad$ significativa $\quad(\mathrm{p}<0,01)$. Contudo, observa-se pouca adaptação em termos da possibilidade de variação do isolamento térmico da roupa ao longo do dia, acompanhando a variação horária de temperatura. Por outro lado, verifica-se variação nas diferentes tipologias, aparentemente em função dos usos (passagem e/ou permanência). Por fím, observa-se valor médio para verão conforme previsto, mas valor de inverno inferior à predição, estando bastante próximo ao valor de verão. Como consideração final, observa-se que a população levantada, tanto em situação de verão quanto em situação de inverno, apresentou nas situações microclimáticas, em geral, menores variações em termo de isolamento térmico da roupa do que o esperado. São necessários novos levantamentos, estabelecidos em uma quantidade de dias mais significativa, para observar-se se a tendência verifica-se.

\section{Temperatura do ar média mensal}

O valor de temperatura do ar média mensal considera a adaptação em função da exposição a condições climáticas prévias, utilizando-se, além dos resultados dos levantamentos empíricos, dados climáticos de séries temporais de estações meteorológicas. Os dados utilizados foram registrados pela Estação Meteorológica da Seção Técnica de Serviços Meteorológicos do Instituto de Astronomia, Geofísica e Ciências Atmosféricas da Universidade de São Paulo, registrada junto à Organização Meteorológica Mundial sob o número 83004 e situada no Parque Estadual das Fontes do Ipiranga, no bairro da Água Funda, à latitude $23^{\circ} 39^{\prime} \mathrm{S}$ e à longitude $46^{\circ} 37^{\prime} \mathrm{W}$ (INSTITUTO..., 2011).

Os dados do ano climático de referência (TRY: Test Reference Year) considerado são apresentados por Goulart, Lamberts e Firmino (1997). O ano climático de referência, segundo Goulart (1993), é constituído por meio da eliminação de anos cujos dados contenham temperaturas médias mensais altas ou baixas, até que se obtenha apenas um ano de dados médios, sendo, portanto, um ano sem extremos de temperatura, constituindo-se em uma situação referencial do clima em questão.

Considerando-se os valores de temperatura equivalente percebida de neutralidade para os dias de verão e inverno dos dois anos em que foram realizados os levantamentos na Cidade Universitária e as temperaturas médias dos 30 dias anteriores a cada dia de levantamento, Monteiro e Alucci (2009c) apresentam a Equação 6 a seguir.

$\mathrm{TEP}_{\mathrm{n}}=20,033+0,1742 \cdot \mathrm{t}_{\mathrm{m}}$

Eq. 6

Com base na equação anterior, pode-se propor uma correção nos valores de TEP em função da média horária da temperatura do ar nos 30 dias anteriores, conforme Equação 7 que se segue.

$\Delta \mathrm{TEP}=3,362-0,1742 \cdot \mathrm{t}_{\mathrm{m}}$

Eq. 7

Ou, ainda, em termos de sensação térmica, conforme a Equação 8 seguinte. 
$\Delta$ Sens $=0,4401-0,0228 \cdot \mathrm{t}_{\mathrm{m}}$

Eq. 8

Para verificar se a temperatura média horária dos 30 dias anteriores ao levantamento apresenta contribuição para a predição da percepção de sensação térmica, realizou-se regressão linear múltipla, considerando também essa variável. Assim, obteve-se a Equação 9 seguinte.

Sens $=-9,988+0,323 \cdot t_{\mathrm{a}}+0,0851 \cdot \mathrm{t}_{\mathrm{rm}}+0,00908$

- ur $-0,324 \cdot \mathrm{v}_{\mathrm{a}}-0,245 \cdot \mathrm{t}_{\mathrm{m}}$

Eq. 9

Onde:

$\mathrm{r}=0,962$;

$\mathrm{r}^{2}=0,925$;

$\mathrm{r}^{2} \mathrm{aj}=0,905$;

ep $=0,311$; e

$\mathrm{p}<0,001$.

Seguindo a explanação de Monteiro e Alucci (2009c), a correlação entre os resultados da equação e os dados observados em termos de sensação térmica, considerando a temperatura média mensal, é mais elevada $(0,962)$ do que sem essa variável $(0,946)$, sendo ambas significativas $(p<0,001)$. A nova correlação apesenta ainda erro padrão ligeiramente menor $(0,311$ contra 0,321$)$. Ressalta-se que a regressão realizada passou nos testes de normalidade $(\mathrm{P}=0,591)$ e de variância constante $(\mathrm{P}=0,967)$. A Tabela 10 apresenta os resultados para a constante da equação e variáveis.

Pode-se verificar, conforme já observado na regressão inicialmente realizada, que há multicolinearidade entre as variáveis independentes, por meio dos elevados valores de VIF encontrados para temperatura do ar (Tabela 14), temperatura radiante média e umidade relativa. Conforme já colocado, tradicionalmente se adota $\mathrm{VIF}<4$, e quando VIF é igual à unidade não há redundância nas outras variáveis independentes. Verifica-se que $\mathrm{VIF}=3,776$ e $\mathrm{p}=0,001$, indicando que não há multicolinearidade em relação à variável temperatura média mensal e que a mesma é significativa para predição da sensação térmica.

\section{Resultados parciais de temperatura do ar média mensal}

A Figura 9 apresenta o gráfico da temperatura equivalente percebida de neutralidade em função das temperaturas médias mensais, abarcando os limites verificados nos levantamentos da Cidade Universitária. Indicam-se ainda os limites da neutralidade (retas paralelas à reta da equação regredida na Figura 9) e os limites verificados empiricamente nos levantamentos do Bairro da Luz (retas paralelas ao eixo y na Figura 9).

Considerando-se apenas a contribuição da temperatura média horária dos 30 dias anteriores aos levantamentos, tem-se correção na temperatura equivalente percebida de $-0,2{ }^{\circ} \mathrm{C}$ para o caso de verão e de $+0,1{ }^{\circ} \mathrm{C}$ para o caso de inverno, respectivamente devido às temperatura médias de $20,2{ }^{\circ} \mathrm{C}$ e $18,8{ }^{\circ} \mathrm{C}$. Ressalta-se que a temperatura média de neutralidade, ou seja, que leva à ausência de correção na correção original, é de $19,3^{\circ} \mathrm{C}$.

Tabela 14 - Resumo estatístico da constante e das quatro variáveis independentes

\begin{tabular}{l|r|r|r|r|r}
\hline & \multicolumn{1}{|c|}{$\mathbf{c}$} & \multicolumn{1}{c|}{ ep } & \multicolumn{1}{c|}{$\mathbf{t}$} & \multicolumn{1}{c}{ p } & VIF \\
\hline Constante & $-9,988$ & 1,685 & $-5,926$ & $<0,001$ & \\
$\mathrm{t}_{\mathrm{ar}}$ & 0,323 & 0,107 & 3,001 & 0,005 & 113,915 \\
$\mathrm{t}_{\mathrm{rm}}$ & $-0,0851$ & 0,0604 & $-1,409$ & 0,167 & 47,362 \\
$\mathrm{ur}$ & 0,00908 & 0,0133 & 0,683 & 0,499 & 18,195 \\
$\mathrm{v}_{\mathrm{ar}}$ & $-0,324$ & 0,100 & $-3,223$ & 0,003 & 2,583 \\
$\mathrm{t}_{\mathrm{m}}$ & 0,245 & 0,132 & 1,856 & 0,001 & 3,776 \\
\hline
\end{tabular}

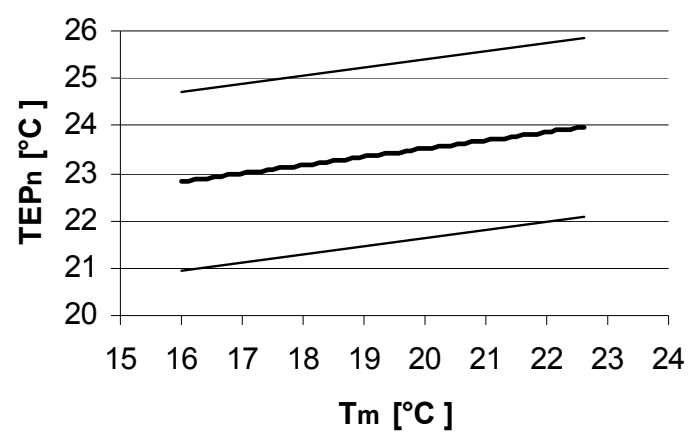

Figura 9 - Temperatura equivalente percebida de neutralidade em função da temperatura do ar média dos 30 dias anteriores

74 Monteiro, L. M.; Alucci, M. P. 


\section{Conclusão acerca dos resultados de temperatura do ar média mensal}

Os levantamentos, em que as correlações de temperatura do ar média horária dos 30 dias prévios foram determinadas, foram realizados apenas em dias de verão e inverno de dois anos consecutivos. Assim, a equação apresentada baseia-se em dados escassos. Contudo, sua verificação demonstrou que, ainda que também dentro de limites estritos, a abordagem que considera a adaptação ante as condições climáticas prévias, por meio da temperatura do ar média horária dos últimos 30 dias, mantém-se.

\section{Análise dos resultados}

Observaram-se as variáveis individuais taxa metabólica e isolamento térmico da roupa, verificando-se limitações nos modelos preditivos. Considerou-se então a variável temperatura do ar média mensal, ou temperatura do ar média horária dos 30 dias prévios, verificando sua contribuição para a predição da sensação térmica.

Assim, considera-se aqui a adaptação às condições climáticas utilizando-se a correlação obtida para a predição da sensação térmica a partir da temperatura de globo e a variação na sensação térmica a partir da temperatura do ar média horária dos 30 dias prévios. A seguinte Equação 10 é, assim, proposta.

Sens' $=-2,736+0,132 \cdot \mathrm{t}_{\mathrm{g}}-0,0228 \cdot \mathrm{t}_{\mathrm{m}} \quad$ Eq. 10

Aplicando-se a equação aos dados de campo do Bairro da Luz, resultados obtidos por meio desse modelo preditivo (Sens'), baseado nos levantamentos laboratoriais da Cidade Universitária, com as sensações térmicas médias observadas nos levantamentos de campo no Bairro da Luz (Sens), tem-se a seguinte regressão linear simples (Equação 11).

Sens' $=-0,367+0,634 \cdot$ Sens

Eq. 11

Onde:

$$
\begin{aligned}
& r=0,928 ; \\
& \text { r2 }=0,861 ; \\
& \text { r2aj=0,854; } \\
& \text { ep }=0,298 ; \text { e } \\
& p<0,001
\end{aligned}
$$

A regressão realizada passou nos testes de normalidade $(\mathrm{P}=0,733)$ e de variância constante $(\mathrm{P}=0,187)$. A Tabela 15 apresenta um resumo dos resultados estatísticos para a constante da equação e a variável independente. A Tabela 16 apresenta análise de variância.

Conforme se pode observar, a regressão realizada é significativa $(\mathrm{p}<0,001)$ e apresenta alta correlação com os dados observados empiricamente $(\mathrm{r}=0,93)$, com valor acima do encontrado sem a consideração da temperatura do ar média horária para os 30 dias prévios $(\mathrm{r}=0,90)$, apresentado por Monteiro Alucci (2010). Tomando-se, assim, a correlação mais significativa obtida com a consideração conjunta da temperatura do ar média horária dos 30 dias prévios, propõe-se a predição da percepção de sensação térmica por meio da Equação 10, apresentada anteriormente, e da formulação de temperatura equivalente de globo (TEG) (Equação 12).

TEG $=24,1+7,6 \cdot$ Sens'

Eq. 12

Assim, considerando-se que a temperatura equivalente de globo é uma temperatura equivalente de sensação, por meio da consideração de sua equação, propõe-se ajuste na temperatura equivalente de globo, por meio da consideração da temperatura do ar média horária dos 30 dias anteriores, a fim de levar em conta o processo de adaptação ante as condições climáticas prévias. Assim, propõe-se a seguinte Equação 13.

$\mathrm{TEG}_{\mathrm{A}}=3,3+\mathrm{t}_{\mathrm{g}}-0,171 \cdot \mathrm{t}_{\mathrm{m}} \quad$ Eq. 13

Onde:

$\mathrm{TEG}_{\mathrm{A}}=$ temperatura equivalente de globo ajustada, em ${ }^{\circ} \mathrm{C}$.

Tabela 15 - Resumo estatístico da constante e variável independente

\begin{tabular}{l|c|c|c}
\hline & Coeficiente & Erro padrão & t \\
\hline Constante & $-0,367$ & 0,0693 & $-5,301$ \\
Sens & 0,634 & 0,0485 & 13,075 \\
\hline
\end{tabular}

Tabela 16 - Análise de variância da regressão linear

\begin{tabular}{l|c|c|r|r|c}
\hline & DF & SS & \multicolumn{1}{c|}{ MS } & F & p \\
\hline Regressão & 1 & 1 & 15,216 & 15,216 & $<0,001$ \\
Resíduo & 42 & 42 & 3,738 & 0,0890 & \\
Total & 43 & 43 & 18,954 & 0,441 & \\
\hline
\end{tabular}


A classificação proposta para a temperatura equivalente de globo ajustada é apresentada na Tabela 17. Para a obtenção da TEG original, basta utilizar $\mathrm{t}_{\mathrm{m}}=19,3{ }^{\circ} \mathrm{C}$, valor anual médio da temperatura do ar para o banco climático de referência da cidade de São Paulo, obtendo-se, assim, o próprio valor de temperatura de globo.

\section{Aplicabilidade dos modelos}

Os modelos foram obtidos a partir de dados compreendidos em determinadas situações ambientais. A utilização em outras situações depende da verificação de correlação de resultados de possíveis extrapolações com dados observados (Tabela 18). Assim, a fim de ressaltar-se a aplicabilidade dos modelos propostos, os limites verificados no levantamento de variáveis ambientais são aqui apresentados juntamente com os limites verificados para a temperatura equivalente de globo, ajustada ou não.

Correlacionando-se a situação ambiental das 72 situações levantadas na Cidade Universitária, por meio da temperatura de globo, e o valor médio de percepção de sensação térmica verificado em cada uma delas (tendo como base os resultados dos 1.750 questionários aplicados), considerando-se a temperatura do ar média horária dos 30 dias anteriores aos levantamentos, e realizando-se a verificação por meio da base empírica levantada no Bairro da Luz, propôs-se a temperatura equivalente de globo ajustada.

A Figura 10 apresenta o gráfico da temperatura de globo de neutralidade $\left(t_{\mathrm{gn}}\right)$ em função das temperaturas médias mensais do ar $\left(\mathrm{t}_{\mathrm{m}}\right)$, abarcando os limites constantes no ano climático de referência para a cidade de São Paulo, segundo Goulart, Lamberts e Firmino (1997).

A Figura 10 indica ainda os limites da neutralidade, segundo as faixas interpretativas propostas. Conforme pode ser observado no gráfico, a temperatura de globo de neutralidade varia de $21,6{ }^{\circ} \mathrm{C}$ a $26,6{ }^{\circ} \mathrm{C}$, ou seja, é de $24,1{ }^{\circ} \mathrm{C}$ $\pm 2,5^{\circ} \mathrm{C}$.

Tabela 17 - Interpretação da TEG $_{\mathrm{A}}$

\begin{tabular}{cc}
\hline TEG $_{\mathrm{A}}$ & Sensação \\
\hline$>43,1$ & muito calor \\
$35,6 \sim 43,1$ & calor \\
$28,0 \sim 35,5$ & pouco calor \\
$20,3 \sim 27,9$ & neutralidade \\
$12,7 \sim 20,2$ & pouco frio \\
$5,1 \sim 12,6$ & frio \\
$<5,1$ & muito frio \\
\hline
\end{tabular}

Tabela 18 - Valores-limite das variáveis envolvidas na TEG e $\mathrm{TEG}_{\mathrm{A}}$, considerando-se os dados observados

\begin{tabular}{c|c|c}
\hline \multirow{2}{*}{ variável } & $\begin{array}{c}\text { valor mínimo observado } \\
{ }^{\mathbf{0}} \mathbf{C}\end{array}$ & $\begin{array}{c}\text { valor máximo observado } \\
{ }^{\mathbf{0}} \mathbf{C}\end{array}$ \\
\hline $\mathrm{t}_{\mathrm{g}}$ & 16,0 & 43,2 \\
$\mathrm{t}_{\mathrm{m}}$ & 16,0 & 22,6 \\
$\mathrm{TEG}$ & 16,0 & 43,2 \\
$\mathrm{TEG}_{\mathrm{A}}$ & 16,6 & 42,6 \\
\hline
\end{tabular}

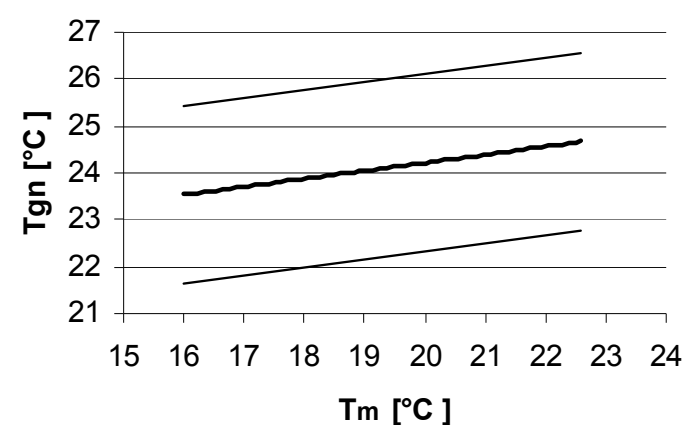

Figura 10 - Temperatura de globo de neutralidade em função da temperatura do ar média dos 30 dias anteriores

76 Monteiro, L. M.; Alucci, M. P. 


\section{Conclusões}

O modelo preditivo temperatura equivalente de globo apresenta-se como modelo de sensação térmica empírico para aplicação em levantamentos in loco em espaços urbanos abertos na cidade de São de Paulo, que, baseando-se apenas na temperatura de globo, requer a utilização de apenas um instrumento quando o objetivo dos levantamentos empíricos for estabelecer correlações com sensações térmicas, facilitando a execução dos levantamentos. A temperatura equivalente de globo apresenta resultados bastante satisfatórios por considerar as trocas convectivas e radiantes (globo cinza, conforme indicado pela norma ISO 7726 (INTERNATIONAL..., 1998)). O índice não considera as trocas úmidas, mas, conforme afirmado por de Dear, Brager e Cooper (1997), para ambientes internos naturalmente ventilados, o fato de os usuários estarem acostumados a determinada condição de umidade faz com que esta não seja variável preponderante na avaliação do conforto térmico. Os resultados encontrados nesta pesquisa, para espaços urbanos abertos, corroboram a afirmação para esta outra tipologia.

No presente artigo, o objetivo era verificar possíveis meios de adaptação térmica (atividades, vestimentas, aclimatação) para proposição de ajustes na temperatura equivalente de globo. Com relação às atividades, consideradas por meio das taxas metabólicas, verificou-se que a variação na sensação térmica é consideravelmente menor do que o previsto nas simulações. Essa verificação é passível de um maior número de observações e também em outras situações ambientais. Com relação às vestimentas, consideradas por meio do isolamento térmico da roupa, verificou-se pouca adaptação em termos da possibilidade de variação do isolamento térmico da roupa ao longo do dia. Por outro lado, verificou-se variação significativa nas diferentes tipologias, aparentemente em função dos usos. Observou-se, ainda, valor médio para verão conforme previsto, mas valor de inverno inferior à predição, estando bastante próximo ao valor de verão. Como consideração final, no geral, verificaram-se menores variações em termo de isolamento térmico da roupa do que o previsto nas simulações. Assim, são necessários novos levantamentos, estabelecidos em uma quantidade de dias mais significativa.

Com relação à aclimatação, considerada por meio da temperatura do ar média horária dos 30 dias anteriores, observou-se que os levantamentos foram realizados apenas em dias de verão e inverno de dois anos consecutivos, levando a uma equação baseada em dados relativamente escassos.
Contudo, sua verificação demonstrou que, ainda que dentro dos limites estabelecidos, a abordagem que considera a adaptação ante as condições climáticas prévias é adequada. Assim, por meio da consideração dessa equação, propôs-se ajuste na temperatura equivalente de globo, utilizando-se a temperatura do ar média dos 30 dias anteriores, a fim de levar em conta o processo de adaptação ante as condições climáticas prévias.

Ressalta-se, por fim, que os resultados desse modelo, conforme verificado, apresentam correlação alta e significativa com os dados observados de percepção de sensação térmica, possibilitando, ainda, predição de fácil aplicação ao realizarem-se medições in loco.

\section{Referências}

BARBOSA, E. T.; AMO, V. A.; LABAKI, L. C. A Influência da Vegetação e das Variáveis Climáticas no Nível de Conforto dos Usuários da Praça do Centro de Convivência em Campinas, SP. In: ENCONTRO NACIONAL DE TECNOLOGIA NO AMBIENTE CONSTRUÍDO, 13., Canela, 2010. Anais... Canela: ANTAC, 2010.

BLAZEJCZYK, K. Climatological-andPhysiological Model of the Human Heat Balance Outdoor and Its Applications in Bioclimatological Studies in Different Scales. Zeszyty IGiPZ PAN, v. 28, p. 27-58, 1996.

BRUSANTIN, G. N.; FONTES, M. S. G. C. Conforto Térmico em Espaços Públicos de Oermanência: uma experiência na cidade de Bauru, SP. In: ENCONTRO NACIONAL SOBRE CONFORTO NO AMBIENTE CONSTRUIIDO, 10.; ENCONTRO LATINO-AMERICANO SOBRE CONFORTO NO AMBIENTE CONSTRUÍDO, 6., Natal, 2009. Anais... Natal: ANTAC, 2009.

DACANAL C. et al. Conforto Térmico em Espaços Livres Públicos: estudo decaso em Campinas, SP. In: ENCONTRO NACIONAL SOBRE CONFORTO NO AMBIENTE CONSTRUÍDO, 10.; ENCONTRO LATINOAMERICANO SOBRE CONFORTO NO AMBIENTE CONSTRUÍDO, 6., Natal, 2009. Anais... Natal: ANTAC, 2009.

DE DEAR, R.; BRAGER, G.; COOPER, D. Developing an Adaptive Model of Thermal Comfort and Preference. Final Report, ASHRAE RP-884, Macquire University, 1997.

DOMINGUEZ, S. A. et al. Control Climatico en Espacios Abiertos: el proyecto Expo'92. Sevilla: Universidad de Sevilla, 1992. 
FONTES, M. S.; BRUSSANTIN, G. Limites de Conforto Térmico em Um Espaço Público de Permanência Arborizado. In: ENCONTRO NACIONAL SOBRE CONFORTO NO AMBIENTE CONSTRUÍDO, 11.; ENCONTRO LATINO-AMERICANO SOBRE CONFORTO NO AMBIENTE CONSTRUÍDO, 7., Armação de Búzios, 2011. Anais... Armação de Búzios: ANTAC, 2011.

GOUlart, S. Dados Climáticos Para Avaliação de Desempenho Térmico de Edificações em Florianópolis. $111 \mathrm{f}$. Florianópolis, 1993. Dissertação (Mestrado em Engenharia Civil) - Escola de Engenharia, Universidade Federal de Santa Catarina, Florianópolis, 1993.

GOULART, S.; LAMBERTS, R.; FIRMINO, S. Dados Climáticos Para Projeto e Avaliação Energética de Edificações Para 14 Cidades Brasileiras. Florianópolis: UFSC, 1997.

HIRASHIMA, S. Q. da S.; ASSIS, E. S. de; FERREIRA, D. G. Calibração do Índice de Conforto Térmico Temperatura Equivalente Tisiológica (PET) para Espaços Abertos do Município de Belo Horizonte, MG. In: ENCONTRO NACIONAL SOBRE CONFORTO NO AMBIENTE CONSTRUÍDO, 11.; ENCONTRO LATINO-AMERICANO SOBRE CONFORTO NO AMBIENTE CONSTRUIIDO, 7., Armação de Búzios, 2011. Anais... Armação de Búzios: ANTAC, 2011.

HIRASHIMA, S. Q. S. Calibração do Índice de Conforto Térmico Temperatura Fisiológica Equivalente (PET) Para Espaços Abertos do Município de Belo Horizonte, MG. Dissertação (Mestrado em Engenharia Civil) - Escola de Engenharia, Universidade Federal de Minas Gerais, Belo Horizonte, 2010.

INSTITUTO DE ASTRONOMIA, GEOFÍSICA E CIÊNCIAS ATMOSFÉRICAS DA UNIVERSIDADE DE SÃO PAULO.

Laboratório de Micrometeorologia. São Paulo, 2011. Disponível em:

$<$ www.iag.usp.br/meteo/labmicro>. Acesso em: 01 jul. 2011.

\section{INTERNATIONAL ORGANIZATION} STANDARDIZATION. ISO 10551: ergonomics of the thermal environment: assessment of the influence of the thermal environment using subjective judgement scales. Genève, 1995.

\section{INTERNATIONAL ORGANIZATION}

STANDARDIZATION. ISO 9920: ergonomics of the thermal environment: estimation of thermal insulation and water vapour resistance of a clothing ensemble. Genève, 1995.
INTERNATIONAL ORGANIZATION STANDARDIZATION. ISO 8996: ergonomics of the thermal environment: determination of metabolic rate. Genève, 1990.

\section{INTERNATIONAL ORGANIZATION}

STANDARDIZATION. ISO 7726: ergonomics of the thermal environment: instruments for measuring physical quantities. Genève, 1998.

MONTEIRO, L. M. Modelos Preditivos de Conforto Térmico: quantificação de relações entre variáveis microclimáticas e de sensação térmica para avaliação e projeto de espaços abertos. 378 f. São Paulo, 2008. Tese (Doutorado em Engenharia Civil) - Escola de Engenharia, Universidade de São Paulo, São Paulo, 2008.

MONTEIRO, L. M. Verificação Comparativa da Predição de Sensação Térmica por Meio de Simulações Computacionais e de Levantamentos Empíricos em Espaços Urbanos da Cidade de São Paulo. 318 f. Relatório (PósDoutorado) - Faculdade de Arquitetura e Urbanismo, Universidade de São Paulo, São Paulo, 2011.

MONTEIRO, L. M.; ALUCCI, M. P. Comparação Cruzada Entre Pesquisas Laboratoriais e de Campo em Conforto Térmico em Espaços Urbanos Abertos. Ambiente Construído, Porto Alegre, v. 10, n. 4, p. 79-101, out./dez. 2010.

MONTEIRO, L. M.; ALUCCI, M. P. Conforto Térmico em Espaços Abertos: parte 1, consideração de variáveis ambientais. In: ENCONTRO NACIONAL SOBRE CONFORTO NO AMBIENTE CONSTRUIIDO, 10.; ENCONTRO LATINO-AMERICANO SOBRE CONFORTO NO AMBIENTE CONSTRUÍDO, 6., Natal, 2009. Anais... Natal: ANTAC, 2009a.

MONTEIRO, L. M.; ALUCCI, M. P. Conforto Térmico em Espaços Abertos: parte 2, consideração da taxa metabólica e do isolamento térmico da roupa. In: ENCONTRO NACIONAL SOBRE CONFORTO NO AMBIENTE CONSTRUÍDO, 10; ENCONTRO LATINOAMERICANO SOBRE CONFORTO NO AMBIENTE CONSTRUÍDO, 6., Natal, 2009. Anais... Natal: ANTAC, 2009b.

MONTEIRO, L. M.; ALUCCI, M. P. Conforto Térmico em Espaços Abertos: parte 3, consideração da aclimatação, sexo e adaptação. In: ENCONTRO NACIONAL SOBRE CONFORTO NO AMBIENTE CONSTRUIIDO, 10; ENCONTRO LATINO-AMERICANO SOBRE CONFORTO NO AMBIENTE CONSTRUIIDO, 6., Natal, 2009. Anais... Natal: ANTAC, 2009c. 
PRATA-SHIMOMURA, A.; MONTEIRO, L. M.; FROTA, A. Temperature of Equivalent Perception Index Applied to Wind Tunnel Erosion Technique Pictures for the Assessment of Pedestrian Thermal Comfort. In: INTERNATIONAL CONFERENCE ON URBAN CLIMATE, 7., YOKOHAMA, 2009. Proceedings... Tokyo: Tokyo Institute of Technology, 2009.

RANCURA, R.; LABAKI, L. C. Conforto Térmico em Espaços Externos: feiras livres em Indaiatuba, SP. In: ENCONTRO NACIONAL SOBRE CONFORTO NO AMBIENTE CONSTRUÍDO, 11.; ENCONTRO LATINOAMERICANO SOBRE CONFORTO NO AMBIENTE CONSTRUÍDO, 7., Armação de Búzios, 2011. Anais... Armação de Búzios: ANTAC, 2011.

ROSSI, F. A. Conforto Térmico em Espaços Abertos em Curitiba. Curitiba, 2010. Memorial de Qualificação de Doutorado. Universidade Tecnológica Federal do Paraná, Curitiba, 2010.

ROSSI, F. A.; KRÜGER, E.; NIKOLOPOULOU, M. A Influência da Configuração Urbana no Microclima e na Sensação Térmica em Ruas de Pedestre de Curitiba, Paraná. In: ENCONTRO NACIONAL SOBRE CONFORTO NO AMBIENTE CONSTRUIIDO, 11.; ENCONTRO LATINO-AMERICANO SOBRE CONFORTO NO AMBIENTE CONSTRUÍDO, 7., Armação de Búzios, 2011. Anais... Armação de Búzios: ANTAC, 2011a.

ROSSI, F. A.; KRÜGER, E.; BRÖDE, P. Definição de Faixas de Estresse Térmico Para Espaços Abertos em Curitiba, Paraná. In: ENCONTRO NACIONAL SOBRE CONFORTO NO AMBIENTE CONSTRUIIDO, 11.; ENCONTRO LATINO-AMERICANO SOBRE CONFORTO NO AMBIENTE CONSTRUÍDO, 7., Armação de Búzios, 2011. Anais... Armação de Búzios: ANTAC, 2011 b.
SHIMAKAWA, A. H.; BUENO-

BARTHOLOMEI, C. L. Aplicação dos Modelos Preditivos de Conforto PET e PMV em Presidente Prudente-SP: estudo de caso Parque doPovo. In: ENCONTRO NACIONALSOBRE CONFORTO NO AMBIENTE CONSTRUIIDO, 10.; ENCONTRO LATINO-AMERICANO SOBRECONFORTO NO AMBIENTE CONSTRUÍDO, 6., Natal, 2009. Anais... Natal: ANTAC, 2009.

SHINYASHIKI, L. A. V.; BUENO-

BARTHOLOMEI, C. L. Praça Nove de Julho: o conforto térmico em espaços públicos abertos na cidade de Presidente Prudente, SP. In:

ENCONTRO NACIONAL SOBRE CONFORTO

NO AMBIENTE CONSTRUÍDO, 11.; ENCONTRO LATINO-AMERICANO SOBRE CONFORTO NO AMBIENTE CONSTRUÍDO, 7., Armação de Búzios, 2011. Anais... Armação de Búzios: ANTAC, 2011.

VOGT, J. et al. A Thermal Environment in Physiologically Significant Terms. Archives for Meteorology, Geophysics and Bioclimatology, v. 29, p. 313-326, 1981.

WOLFRAM, B. R.; MONTEIRO, L. M. Avaliação da Influência da Arborização no Conforto Térmico do Pedestre em Meio Urbano: estudo de caso em espaços abertos do Bairro da Luz, São Paulo, SP. In: ENCONTRO NACIONAL SOBRE CONFORTO NO AMBIENTE CONSTRUÍDO, 11.; ENCONTRO LATINOAMERICANO SOBRE CONFORTO NO AMBIENTE CONSTRUÍDO, 7., Armação de Búzios, 2011. Anais... Armação de Búzios: ANTAC, 2011.

\section{Agradecimentos}

À Fundação de Amparo à Pesquisa do Estado de São Paulo (Fapesp) e ao Conselho Nacional de Desenvolvimento Científico e Tecnológico (CNPq).

Revista Ambiente Construído

Associação Nacional de Tecnologia do Ambiente Construído

Av. Osvaldo Aranha, 99 - 30 andar, Centro

Porto Alegre - RS - Brasil

CEP $90035-190$

Telefone: +55 (51) 3308-4084

Fax: +55 (51) 3308-4054

www. seer. ufrgs. br/ ambienteconstruido

E-mail: ambienteconstruido@ufrgs.br 